\title{
Knowledge, Attitudes, and Interactions with Chaplains and Nursing Staff Outcomes: A Survey Study
}

\section{Tara Liberman $^{1} \cdot$ Andrzej Kozikowski ${ }^{2}$ Maria Carney ${ }^{1} \cdot$ Myriam Kline $^{3}$. Abraham Axelrud ${ }^{4} \cdot$ Alexandra Ofer $^{1} \cdot$ Michelle Rossetti $^{1} \cdot$ Renee Pekmezaris $^{2}$}

Published online: 22 May 2020

○) Springer Science+Business Media, LLC, part of Springer Nature 2020

\begin{abstract}
We conducted a cross-sectional survey of nursing staff $(n=51)$ in an academic hospital finding a significant inverse relationship between the frequency of chaplaincy interaction and perceived stress $(r=-0.27, p=0.05)$. We also found a significant positive relationship between rated importance of having a chaplain at the hospital and secondary trauma $(r=0.30, p=0.03)$. There was a significant positive relationship between religiosity and rated importance for having a chaplain $(r=0.30$, $p=0.03)$ and rated helpfulness of chaplains $(r=0.32, p=0.02)$. Similarly, there was a significant positive relationship between spirituality and average length of conversations with a chaplain, rated importance for having a chaplain, and helpfulness of chaplains $(r=0.32, p=0.03 ; r=0.44, p=0.001$; and $r=0.52, p=0.0001$, respectively). Interaction with chaplains is associated with decreased employee perceived stress for nursing staff who provide care for severely ill patients.
\end{abstract}

Keywords Chaplaincy $\cdot$ Nursing staff stress $\cdot$ Religiosity

\section{Introduction}

Spiritual care is a vital component of quality palliative care. Chaplains provide patients with a multitude of essential services including moral, emotional and psychological support, religious and spiritual guidance, and assistance to the patient's

Andrzej Kozikowski

Akozikowski@Northwell.edu

1 Division of Health Services Research, Department of Medicine, Center for Health Innovations and Outcomes Research, Northwell Health, 600 Community Drive 4th floor, Manhasset, NY 11030, USA

2 Department of Medicine, Northwell Health, 175 Community Dr., Second Floor, Great Neck, NY 11021, USA

3 Division of Biostatistics, Feinstein Institute for Medical Research, Manhasset, NY 11030, USA

4 Department of Chaplaincy, Northwell Health, New Hyde Park, NY 11040, USA 
family - all in an effort to relieve suffering and to help patients and their family engage their coping resources to face difficult life circumstances (Chang et al. 2012). Jeuland et al. (2017) conducted a national survey in the US to assess chaplain integration into palliative care and their work activities in this setting. The researchers found that over half of the chaplains in the study indicated that they frequently participated in palliative care rounds, provided care for patients at the time of death, visited patients to build relationships, engaged in goals of care conversations and assisted patients with spiritual matters. However, patients are not the only ones interacting with chaplains in healthcare settings. Chaplains frequently provide consultation and support to medical staff in palliative and hospice care, intensive care units (ICU), cardiothoracic intensive care units and other medical care settings. The physicians, allied health employees and support staff in such workplaces are often confronted with death and dying and have to make difficult decisions, which may contribute to their suffering in the form of burnout, stress, vicarious trauma, moral distress and compassion fatigue (Pereira et al. 2011).

Various studies have investigated compassion fatigue, caregiver stress, and burnout in health employees (Brindley et al. 2012; El-bar et al. 2013; Hooper et al. 2010; Lyckholm 2001; Najjar et al. 2009; Shanafelt and Dyrbye 2012; Sherman et al. 2006). Research suggests that burnout, psychosocial distress, and compassion fatigue are high among medical staff including oncology physicians, nurses, social workers, hospice and palliative care physicians, and other health workers (Brindley et al. 2012; El-bar et al. 2013; Hooper et al. 2010; Lyckholm 2001; Najjar et al. 2009; Shanafelt and Dyrbye 2012; Sherman et al. 2006). Campbell et al. (2001) for example, utilizing a sample of 582 American surgeons, found that $32 \%$ had increased levels of emotional exhaustion and $13 \%$ experienced high levels of depersonalization. Stress and burnout in health care employees result in decreased job satisfaction and increased rates of turnover (Coomber and Louise Barriball 2007; Grunfeld et al. 2000; Whitebird et al. 2013). Pfaff et al. (2017) have shown in their preliminary study that a compassion fatigue resiliency program was effective in mitigating healthcare employees' clinical stress in a cancer center.

Research shows that stress in health care settings often contains a moral component (Lützén et al. 2003; Rathert et al. 2016; Sajjadi et al. 2017). Stress related to one's conscience has been associated with burnout in the hospital and primary care (Glasberg et al. 2006). Glasberg et al. conducted a cross-sectional study with a sample of 423 healthcare personnel finding that $59 \%$ of the variance in emotional exhaustion was explained by "having to deaden one's conscience" and "stress of conscience" from lacking time to provide the care needed, work being demanding to the extent that it influences home life, and not being able to live up to others' expectations.

Conscience also seems to play a role in nurse behaviors. Jensen and Lidell (2009) sought to describe nurses' conceptions of their conscience's influence on inpatient care provision. The results showed that nurses considered conscience to be a major factor in their work serving as an influencing force, a restricting component and an antecedent of sensitivity. Nurses perceived that conscience was critical in influencing their behaviors toward patients and their family guiding their efforts to provide exceptional care. A questionnaire study of how personnel in various healthcare 
settings perceive conscience (i.e., where people think conscience comes from and what its qualities and functions are) showed that it was often viewed as an authority and a useful and valuable guide but also a burden, and a warning signal demanding attention (Dahlqvist et al. 2007).

Zuzelo (2007) conducted a study investigating nurses' moral distress events and their frequency. The researcher found that the most frequently reported morally distressing events were working with staffing levels that were perceived as unsafe, following families' wishes for patient care even though the nurse disagreed with the plan, and continuing futile life support for patients due to family wishes despite patients' poor prognoses. When medical staff are prevented from doing what they perceive to be right, they may experience internal conflict, thereby giving rise to a troubled conscience. Interestingly, Zuzelo (2007) also found in her qualitative analysis that nurses sought support and information from chaplaincy services, nurse managers, and other colleagues.

In another study, Cronqvist et al. (2006) described nurses' moral stress in an intensive care nursing setting. The main findings of the study revealed that dealing with moral stress was experienced as a private matter that colleagues who managed moral stress served as models in support and not being able to cope with moral stress urged participants to seek outside help. These findings suggest that having an available chaplain on site could provide much-needed support to alleviate the moral and conscience related stressors often experienced by medical personnel. Research shows that providers perceived chaplains favorably as valuable resources in the hospital setting (Cunningham et al. 2017).

However, there have only been a few studies exploring how interacting with a chaplain may affect hospital staff outcomes (Fitchett 2017). In a qualitative study, Hemming et al. (2016) investigated the benefits and challenges of having internal medicine residents and chaplain interns participate in an inter-professional curriculum in the clinical setting. One of the main findings was that the medical team perceived chaplains to be an essential source of emotional support, particularly in difficult circumstances such as when dealing with death and dying in the hospital. In another qualitative study utilizing a phenomenological design, Taylor et al. (2015) examined the shared experience between hospital chaplains and hospital-based healthcare providers who received spiritual care from the chaplains. The results showed that chaplains often helped providers in both professional (e.g., hospital decisions) and personal matters (e.g., the death of a relative). Moreover, Taylor et al. (2015) found that providers appreciated having chaplains in the hospital and all the help they provided to both patients and hospital employees including personal spiritual matters, listening to problems and providing non-judgmental and emotionally supporting presence. In a small pilot intervention study, Charlescraft et al. (2014) found that chaplains served an important role for pediatric intensive care nurses and improved their ability to cope with stress at work.

More research is needed to better understand how chaplains can assist their colleagues in the hospital setting (Fitchett 2017). Except for the above-mentioned preliminary findings, there has not been any research investigating the relationship between frequency and intensity of interacting with a chaplain on the job and healthcare employee perceived stress and compassion fatigue. Additionally, there 
is a paucity of research investigating whether increased frequency and intensity of interacting with a chaplain is associated with a higher level of job satisfaction in health care employees caring for severely ill patients. Thus, our primary objective for the current study was to investigate whether chaplaincy interaction is associated with decreased employee stress and increased job satisfaction.

\section{Methods}

After obtaining Institutional Review Board approval, we conducted an anonymous cross-sectional survey study of nursing staff who have a chaplain available on daily rounds in an academic, tertiary care hospital in the New York metropolitan area. Utilizing a purposive sampling strategy, we surveyed employees regarding their perceived stress, compassion fatigue, job satisfaction, and religiosity/spirituality and assess whether the degree of interaction with a chaplain in daily rounds is associated with our measures. Specifically, we evaluated whether more interaction with a chaplain is associated with: (1) decreased compassion fatigue (two dimensions: job burnout and secondary trauma), (2) decreased perceived stress, and (3) increased job satisfaction. Moreover, we also assessed if respondents' religiosity and spirituality are associated with the frequency of interacting with a chaplain and whether the length of time working in the hospital is associated with awareness, knowledge, attitudes toward and interactions with hospital chaplains.

\section{Measures}

To assess general perception of stress, we utilized the psychometrically valid Perceived Stress Scale (PSS) (Cohen 1988). The items in the PSS assess feelings and thoughts related to stress during the last month using a 5-point scale with 0 being never and 4 being very often.

The second measure utilized was the Compassion Fatigue Scale (CFS) (Adams et al. 2006). The CFS scale was designed to assess two dimensions: secondary (or vicarious) trauma and job burnout. The items assessing secondary trauma and job burnout consist of a 10-point, visual, analog-type Likert-type scale (1=never or rarely, $10=$ very often).

\section{Statistical Methods}

Descriptive statistics (mean and standard deviation for continuous variables, proportions for categorical variables) were calculated. Spearman correlation was used to test the relationship between selected questions regarding chaplains and scores on the PSS and CFS (job burnout and secondary trauma dimensions). All analyses were performed using SAS version 9.3 (SAS Institute, Inc., Cary, NC). 


\section{Results}

\section{Characteristics of Study Participants}

The sample consisted of 51 participants with a mean age of 38.2 (Table 1). Reliability of the three measures utilized demonstrated either acceptable or good reliability with Cronbach coefficient alphas being $0.83,0.77$ and 0.87 for the job burnout, secondary trauma, and PSS, respectively. The majority of the sample were female $(91.3 \%)$ and self-identified as white $(55.3 \%)$, followed by black (12.8\%), Asian (8.5\%), Hispanic (6.4\%), and other (17.0\%). With regard to religious affiliation, most reported being Roman Catholic $(51.1 \%)$, followed by other (17.0\%), Protestant (12.8\%), Jewish (6.4\%), Buddhist (4.3\%), Muslim (2.1\%), Evangelical Christian (2.1\%), Atheist (2.1\%), and Agnostic, (2.1\%). Respondents most frequently reported being 'moderately' religious $(36.7 \%)$ and spiritual $(38.8 \%)$. The majority reported their current position being a nurse $(80.4 \%)$ with more than 10 years in the current position (37.5\%). Most reported being either 'satisfied' $(38.8 \%)$ or 'very satisfied' $(20.4 \%)$ with their current position. On the CFS, the mean job burnout score was 2.4 , and secondary trauma score was 2.1 indicating a very low level of both job burnout and secondary trauma. The mean PSS was 14.0, which is similar to the norms data presented by Cohen (1988).

\section{Awareness and Knowledge of Chaplain Services}

The majority (98.0\%) of respondents indicated being aware that there are chaplain services in the hospital, but only $56.9 \%$ reported knowing what services chaplains provide (Table 2). When asked which services hospital chaplains offer, most indicated spiritual support to patients $(96.1 \%)$, family members $(92.2 \%)$ and hospital staff $(80.4 \%)$. Approximately half $(52.9 \%)$ reported that the chaplain often walks the hospital halls to connect with people who might need spiritual support. Also roughly half $(47.1 \%)$ indicated that the chaplain assists members of the staff who may be struggling with religious issues. The majority $(88.2 \%)$ disagreed that the chaplain only provides spiritual assistance to patients and family members and never to hospital staff. With regard to differences between nursing staff who have worked at the hospital for 10 years or less versus those with more than 10 years, there were no significant differences in awareness and knowledge of chaplain services.

\section{Attitudes Toward and Interactions with a Hospital Chaplain}

When asked whom participants talk with during stressful situations encountered in the hospital, respondents most frequently reported co-workers $(74.5 \%)$, followed by family $(51.0 \%)$, and friends $(39.2 \%)$ (Table 3). Only $11.8 \%$ indicated that they talk with a chaplain during stressful situations. The majority (74.5\%) reported appreciating having a chaplain in the hospital. Approximately half $(52.9 \%)$ of participants indicated 'never' when asked how often they talk with a chaplain followed by 'less 
Table 1 Characteristics of study participants $(N=51)$

\begin{tabular}{|c|c|}
\hline Variable & $n(\%)$ \\
\hline \multicolumn{2}{|l|}{ Age } \\
\hline Mean (SD) & $38.2(11.8)$ \\
\hline Median & 36.0 \\
\hline \multicolumn{2}{|l|}{ Gender } \\
\hline Female & $42(91.3)$ \\
\hline Male & $4(8.7)$ \\
\hline \multicolumn{2}{|l|}{ Racelethnicity } \\
\hline White & $26(55.3)$ \\
\hline Black & $6(12.8)$ \\
\hline Asian & $4(8.5)$ \\
\hline Hispanic & $3(6.4)$ \\
\hline Other & $8(17.0)$ \\
\hline \multicolumn{2}{|l|}{ Religious affiliation } \\
\hline Roman Catholic & $24(51.1)$ \\
\hline Protestant Christian & $6(12.8)$ \\
\hline Jewish & $3(6.4)$ \\
\hline Buddhist & $2(4.3)$ \\
\hline Muslim & $1(2.1)$ \\
\hline Evangelical Christian & $1(2.1)$ \\
\hline Atheist & $1(2.1)$ \\
\hline Agnostic & $1(2.1)$ \\
\hline Other & $8(17.0)$ \\
\hline \multicolumn{2}{|l|}{ Religiosity } \\
\hline Not at all & $4(8.0)$ \\
\hline Slightly & $10(20.4)$ \\
\hline Neutral & $8(16.3)$ \\
\hline Moderately & $18(36.7)$ \\
\hline Very & $9(18.4)$ \\
\hline \multicolumn{2}{|l|}{ Spirituality } \\
\hline Not at all & $4(8.2)$ \\
\hline Slightly & $6(12.2)$ \\
\hline Neutral & $5(10.2)$ \\
\hline Moderately & $19(38.8)$ \\
\hline Very & $15(32.6)$ \\
\hline \multicolumn{2}{|l|}{ Current position } \\
\hline Nurse & $37(80.4)$ \\
\hline Certified nursing assistant & $1(2.2)$ \\
\hline Other & $8(17.4)$ \\
\hline \multicolumn{2}{|c|}{ Length of time in current position } \\
\hline Less than 1 year & $2(4.2)$ \\
\hline $1-2$ years & $8(16.7)$ \\
\hline $3-4$ years & $9(18.8)$ \\
\hline $5-7$ years & $6(12.5)$ \\
\hline
\end{tabular}


Table 1 (continued)

\begin{tabular}{ll}
\hline Variable & $n(\%)$ \\
\hline 8-10 years & $5(10.4)$ \\
More than 10 years & $18(37.5)$ \\
Satisfaction with position & \\
Very dissatisfied & $2(4.1)$ \\
Dissatisfied & $2(4.1)$ \\
Somewhat dissatisfied & $7(14.3)$ \\
Neutral & $9(18.4)$ \\
Somewhat satisfied & $0(0.0)$ \\
Satisfied & $19(38.8)$ \\
Very satisfied & $10(20.4)$ \\
Job burnout & \\
Mean (SD) & $2.4(1.4)$ \\
Median & 2.0 \\
Secondary trauma & \\
Mean (SD) & $2.1(1.3)$ \\
Median & 1.6 \\
Perceived stress & 14.0 \\
Mean (SD) & \\
Median & \\
\hline & \\
\hline
\end{tabular}

than once a month' (19.6\%) and '2-3 times a week' (11.8\%). For those that reported talking with a chaplain, the most common duration was '1-5 min' (29.6\%). Regarding importance and helpfulness of talking with chaplains, $39.3 \%$ indicated moderately/very important, and $37.3 \%$ reported moderately/very helpful. When asked what the reasons for talking with a chaplain are, respondents indicated 'intense situations with patients' (35.6\%) and 'personal issues' (15.6\%). With regard to differences between nursing staff who have worked at the hospital for 10 years or less versus those that have worked for more than 10 years, there was a significant relationship on the average length of conversations with chaplains $(p=0.006)$. Specifically, nursing staff with 10 or fewer years of working in the hospital were more likely to never talk with a chaplain compared to those with more than 10 years (43.3\% vs. $33.3 \%)$. There were no other significant relationships between length of time working at the hospital and all other attitudes toward and interactions with the hospital chaplain.

\section{Main Results}

The majority of respondents appreciate having a chaplain at the hospital (74.5\%), and believe chaplains provide spiritual support in the hospital environment to staff (80.4\%). Only a small proportion $(11.8 \%)$ believe chaplains solely provide spiritual assistance to patients and family and never to staff. Few (11.8\%) talk to a chaplain during stressful situations at work, and approximately half believe that chaplains 
Table 2 Awareness and knowledge of chaplain services for all participants and by length of time working at the hospital

\begin{tabular}{|c|c|c|c|c|}
\hline \multirow[t]{3}{*}{ Question } & \multirow[t]{2}{*}{ All participants } & \multicolumn{2}{|c|}{ Length of time working at the hospital } & \multirow[t]{3}{*}{$p$ value } \\
\hline & & 10 years or less & More than 10 years & \\
\hline & $n(\%)$ & $n(\%)$ & $n(\%)$ & \\
\hline
\end{tabular}

\begin{tabular}{lccc}
\hline Do you know if there are chaplain services in this hospital? & \\
Yes & $50(98.0)$ & $30(100.0)$ & $17(94.4)$ \\
No & $0(0.0)$ & $0(0.0)$ & $1(5.6)$ \\
Not sure & $1(2.0)$ & $0(0.0)$ & $0(0.0)$
\end{tabular}

Do you know what services chaplains provide in the hospital?

\begin{tabular}{|c|c|c|c|c|}
\hline Yes & $29(56.9)$ & $15(50.0)$ & $12(66.7)$ & 0.584 \\
\hline No & $6(11.8)$ & 4 (13.3) & $2(11.1)$ & \\
\hline Not sure & $16(31.4)$ & $11(36.7)$ & $4(22.2)$ & \\
\hline
\end{tabular}

In general, which of the following are services that hospital chaplains provide?

Chaplain provides spiritual support in the hospital environment to patients

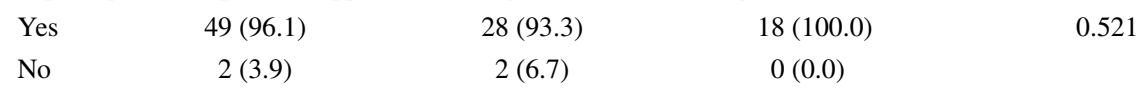

Chaplain provides spiritual support in the hospital environment to hospital staff

\begin{tabular}{|c|c|c|c|}
\hline Yes & $41(80.4)$ & $23(76.7)$ & $16(88.9)$ \\
\hline No & $10(16.6)$ & $7(23.3)$ & $2(11.1)$ \\
\hline
\end{tabular}

Chaplain provides spiritual support in the hospital environment to family members

$\begin{array}{cccc}\text { Yes } & 47(92.2) & 27(90.0) & 17(94.4) \\ \text { No } & 4(7.8) & 3(10.0) & 1(5.6)\end{array}$

Chaplain often walks the halls to connect with people who might need spiritual support

\begin{tabular}{|c|c|c|c|c|}
\hline Yes & $27(52.9)$ & $17(56.7)$ & $9(50.0)$ & 0.654 \\
\hline No & $24(47.1)$ & $13(43.3)$ & $9(50.0)$ & \\
\hline
\end{tabular}

Chaplain provides assistance for members of the staff who may be struggling with religious issues

\begin{tabular}{|c|c|c|c|c|}
\hline Yes & $24(47.1)$ & $15(50.0)$ & $8(44.4)$ & 0.709 \\
\hline No & $27(52.9)$ & $15(50.0)$ & $10(55.6)$ & \\
\hline
\end{tabular}

Chaplain only provides spiritual assistance to patients and family members and never hospital staff

\begin{tabular}{|c|c|c|c|c|}
\hline Yes & $6(11.8)$ & $4(13.3)$ & $2(11.1)$ & 1.000 \\
\hline No & $45(88.2)$ & $26(86.7)$ & $16(88.9)$ & \\
\hline
\end{tabular}

assist members of the staff who may be struggling with religious issues $(47.1 \%$; Fig. 1).

As seen in Table 4, there was a significant inverse relationship between the frequency of talking with a chaplain at the hospital and perceived stress $(n=51$, $r=-0.27, p=0.05)$. Specifically, the less participants reported talking with a chaplain, the greater their perceived stress levels. Moreover, there was a significant inverse relationship between the question item, "Overall, how satisfied are you with your current position at the hospital?" and perceived stress $(n=49, r=-0.32$, $p=0.03$ ). Specifically, the less a participant indicated to be satisfied with their current position, the higher his/her perceived stress. There was also a significant 
Table 3 Attitudes toward and interactions with hospital chaplain for all participants and by length of time working at the hospital

\begin{tabular}{lll}
\hline Question & All participants & $\frac{\text { Length of time working at the hospital }}{2} p$ value \\
$n(\%)$ & $n(\%)$ & $n(\%)$ \\
\hline
\end{tabular}

During stressful situations in the hospital, who do you mostly talk to for support?

Co-workers

$\begin{array}{cllll}\text { Yes } & 38(74.5) & 21(70.0) & 16(88.9) & 0.171 \\ \text { No } & 13(25.5) & 9(30.0) & 2(11.1) & \\ \text { Family } & & & & 0.074 \\ \text { Yes } & 26(51.0) & 18(60.0) & 6(33.3) & 12(66.7) \\ \text { No } & 25(49.0) & 12(40.0) & \end{array}$

Friends

$\begin{array}{lllll}\text { Yes } & 20(39.2) & 14(46.7) & 5(27.8) & 0.195 \\ \text { No } & 31(60.8) & 16(53.3) & 13(72.2) & \\ \begin{array}{l}\text { Chaplain } \\ \text { Yes }\end{array} & 6(11.8) & 3(10.0) & 3(16.7) & 0.658 \\ \text { No } & 45(88.2) & 27(90.0) & 15(83.3) & \end{array}$

Do you appreciate having a chaplain at this hospital?

$\begin{array}{llll}\text { Yes } & 38(74.5) & 22(73.3) & 14(77.8) \\ \text { No } & 1(2.0) & 0(0.0) & 0(0.0) \\ \text { Not sure } & 12(23.5) & 8(26.7) & 4(22.2)\end{array}$

How often do you talk with a chaplain at this hospital?

\begin{tabular}{|c|c|c|c|c|}
\hline Never & $27(52.9)$ & $15(50.0)$ & $10(55.6)$ & 0.957 \\
\hline Less than once a month & $10(19.6)$ & $6(20.0)$ & $3(16.7)$ & \\
\hline Once a month & $3(5.9)$ & $2(6.7)$ & $1(5.6)$ & \\
\hline $2-3$ times a month & $2(3.9)$ & $2(6.7)$ & $0(0.0)$ & \\
\hline Once a week & $3(5.9)$ & $2(6.7)$ & $1(5.6)$ & \\
\hline 2-3 times a week & $6(11.8)$ & $3(10.0)$ & $3(16.7)$ & \\
\hline \multicolumn{5}{|c|}{ On average, how long does your conversation with a chaplain last? } \\
\hline Never talk with a chaplain & $19(43.2)$ & $13(43.3)$ & $4(33.3)$ & \multirow[t]{5}{*}{0.006} \\
\hline Less than a minute & $7(15.9)$ & $4(13.3)$ & $3(25.0)$ & \\
\hline $1-5 \mathrm{~min}$ & 13 (29.6) & $11(36.7)$ & $2(16.7)$ & \\
\hline $6-10 \mathrm{~min}$ & $5(11.4)$ & $2(6.7)$ & $3(25.0)$ & \\
\hline More than $20 \mathrm{~min}$ & $0(0.0)$ & $0(0.0)$ & $0(0.0)$ & \\
\hline \multicolumn{5}{|c|}{ How important is it for you to have a chaplain at this hospital that you can talk to? } \\
\hline Not at all important & $8(15.7)$ & $3(10.0)$ & $4(22.2)$ & \multirow[t]{5}{*}{0.332} \\
\hline Slightly important & $5(9.8)$ & $3(10.0)$ & $1(5.6)$ & \\
\hline Neutral & $18(35.3)$ & $9(30.0)$ & $9(50.0)$ & \\
\hline Moderately important & $6(11.8)$ & $5(16.7)$ & $1(5.6)$ & \\
\hline Very important & $14(27.5)$ & $10(33.3)$ & $3(16.7)$ & \\
\hline
\end{tabular}


Table 3 (continued)

\begin{tabular}{|c|c|c|c|c|}
\hline \multirow[t]{3}{*}{ Question } & \multirow{3}{*}{$\begin{array}{l}\text { All participants } \\
n(\%)\end{array}$} & \multicolumn{2}{|c|}{ Length of time working at the hospital } & \multirow[t]{3}{*}{$p$ value } \\
\hline & & 10 years or less & More than 10 years & \\
\hline & & $n(\%)$ & $n(\%)$ & \\
\hline \multicolumn{5}{|c|}{ How helpful is it for you to have a chaplain at this hospital that you can talk to? } \\
\hline Not at all helpful & $8(15.7)$ & $3(10.0)$ & $4(22.2)$ & \multirow[t]{5}{*}{0.722} \\
\hline Slightly helpful & $6(11.8)$ & $2(6.7)$ & $2(11.1)$ & \\
\hline Neutral & $18(35.3)$ & $12(40.0)$ & $6(33.3)$ & \\
\hline Moderately helpful & $5(9.8)$ & $3(10.0)$ & $2(11.1)$ & \\
\hline Very helpful & $14(27.5)$ & $10(33.3)$ & $4(22.2)$ & \\
\hline \multicolumn{5}{|c|}{ Which of the following are reasons why you talk with a chaplain? } \\
\hline Never talk with a chaplain & $22(48.9)$ & $13(50.0)$ & $8(50.0)$ & \multirow[t]{3}{*}{0.829} \\
\hline Personal issues & $7(15.6)$ & $3(11.5)$ & $3(18.8)$ & \\
\hline Intense situations with patients & $16(35.6)$ & $10(38.5)$ & $5(31.3)$ & \\
\hline
\end{tabular}

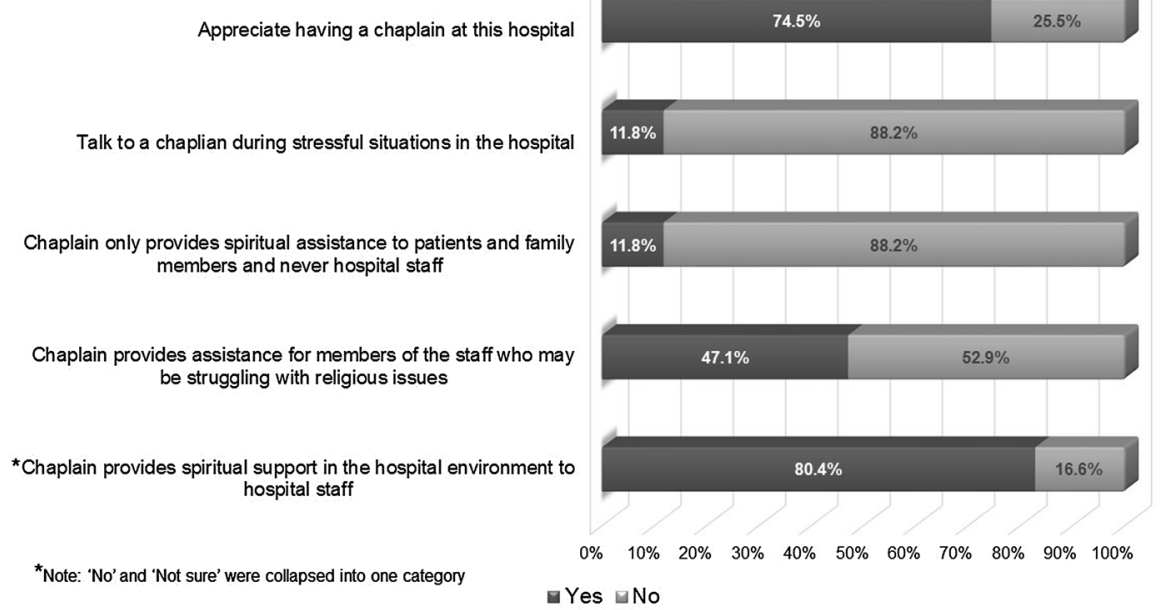

Fig. 1 Nursing staff knowledge and interactions with chaplains

positive relationship between the rated importance of having a chaplain in the hospital to talk to and secondary trauma $(n=49, r=0.30, p=0.03)$.

There was a significant positive relationship between how religious participants rated themselves to be and their rated importance of having a chaplain at the hospital that they can talk to $(n=50, r=0.30, p=0.03)$ (Table 5). The more religious participants reported being, the more important it was for them to have a chaplain to talk to at the hospital. There was also a significant positive relationship between how religious participants rated themselves and the question item "How helpful is it for you 
Table 4 The relationship between attitudes toward and interactions with hospital chaplain and scores on job burnout, secondary trauma, and perceived stress scales

\begin{tabular}{|c|c|c|c|}
\hline Question & Job burnout & Secondary trauma & Perceived stress \\
\hline \multicolumn{4}{|c|}{ How often do you talk with a chaplain at this hospital? } \\
\hline Spearman correlation coefficient & -0.16 & -0.08 & -0.27 \\
\hline$p$ value & 0.28 & 0.57 & 0.05 \\
\hline Number of observations & 49 & 49 & 51 \\
\hline \multicolumn{4}{|c|}{ On average, how long does your conversation with a chaplain last? } \\
\hline Spearman Correlation Coefficient & -0.02 & 0.10 & -0.12 \\
\hline$p$ value & 0.89 & 0.52 & 0.43 \\
\hline Number of observations & 43 & 43 & 44 \\
\hline \multicolumn{4}{|c|}{ How important is it for you to have a chaplain at this hospital that you can talk to? } \\
\hline Spearman correlation coefficient & 0.09 & 0.30 & 0.14 \\
\hline$p$ value & 0.54 & 0.03 & 0.32 \\
\hline Number of observations & 49 & 49 & 51 \\
\hline \multicolumn{4}{|c|}{ How helpful is it for you to have a chaplain at this hospital that you can talk to? } \\
\hline Spearman correlation coefficient & 0.18 & 0.21 & 0.04 \\
\hline$p$ value & 0.21 & 0.14 & 0.76 \\
\hline Number of observations & 49 & 49 & 51 \\
\hline \multicolumn{4}{|c|}{ Overall, how satisfied are you with your current position at the hospital? } \\
\hline Spearman correlation coefficient & -0.27 & -0.17 & -0.32 \\
\hline$p$ value & 0.06 & 0.24 & 0.03 \\
\hline Number of observations & 49 & 49 & 49 \\
\hline \multicolumn{4}{|c|}{ How long have you been working at this hospital? } \\
\hline Spearman correlation coefficient & 0.21 & 0.15 & 0.16 \\
\hline$p$ value & 0.16 & 0.31 & 0.28 \\
\hline Number of observations & 48 & 48 & 48 \\
\hline
\end{tabular}

to have a chaplain at this hospital that you can talk to?" $(n=50, r=0.32, p=0.02)$. The more religious participants reported being, the more helpful it was for them to have a chaplain at the hospital.

Similarly, there was a significant positive relationship between how spiritual participants rated themselves to be and the question item "How important is it for you to have a chaplain at this hospital that you can talk to?" $(n=50, r=0.44, p<0.001)$. Specifically, the more spiritual participants reported being, the more important it was for them to have a chaplain to talk to at the hospital. There was a significant positive relationship between how spiritual participants rated themselves to be and the question item "How helpful is it for you to have a chaplain at this hospital that you can talk to?" $(n=50, r=0.52, p<0.001)$. Specifically, the more spiritual participants reported being, the more helpful it was for them to have a chaplain to talk to at the hospital.

Lastly, we also found a significant positive relationship between how spiritual participants rated themselves to be and the question item "On average, how long 
Table 5 The relationship between attitudes toward and interactions with hospital chaplain and religiosity and spirituality

\begin{tabular}{lcc}
\hline Questions & Religiosity & Spirituality \\
\hline How often do you talk with a chaplain at this hospital? & & \\
Spearman correlation coefficient & 0.10 & 0.25 \\
$p$ value & 0.51 & 0.08 \\
Number of observations & 50 & 50 \\
On average, how long does your conversation with a chaplain last? & & \\
Spearman correlation coefficient & 0.21 & 0.32 \\
$p$ value & 0.18 & 0.03 \\
Number of observations & 44 & 44 \\
How important is it for you to have a chaplain at this hospital that you can talk to? & \\
Spearman Correlation coefficient & 0.30 & 0.44 \\
$p$ value & 0.03 & $<0.001$ \\
Number of observations & 50 & 50 \\
How helpful is it for you to have a chaplain at this hospital that you can talk to? & \\
Spearman correlation coefficient & 0.32 & 0.52 \\
$p$ value & 0.02 & $<0.001$ \\
Number of observations & 50 & 50 \\
\hline
\end{tabular}

does your conversation with a chaplain last?" $(n=44, r=0.32, p=0.03)$. Specifically, the more spiritual, the longer on average, participants reported their conversations lasting with a chaplain.

\section{Discussion}

The primary objective of our study was to investigate whether a greater degree of interaction with a chaplain was associated with decreased employee stress and increased job satisfaction. We found a significant inverse relationship between the frequency of talking with a chaplain and perceived stress. Not surprisingly, we also found that the more religious or spiritual participants were, the higher they rated helpfulness and importance of having a chaplain in the hospital. Moreover, we found that the majority of respondents appreciate having a chaplain at the hospital, and believe chaplains provide spiritual support in the hospital setting to staff; however, only a small proportion talk to a chaplain during stressful situations at work.

Taylor et al. (2015) explored hospital healthcare provider experiences of receiving spiritual support from chaplain services. Through a qualitative phenomenological study utilizing in-depth interviews, the researchers found that participants were aware of and appreciated chaplain services. The researchers also found that participants perceived chaplains to be available to assist medical personnel focused on building relationships with providers and tried to meet their personal and professional needs. In our study, we also found that the overwhelming majority of nursing staff were aware of chaplain services in the hospital and appreciated having a 
chaplain on site. Moreover, the majority indicated that chaplains provide spiritual support not only to patients but also to hospital staff. However, very few reported talking with a chaplain during stressful situations at work.

Except for a few preliminary studies, there is no other research documented in the literature exploring the relationship between chaplaincy and hospital staff outcomes. Stress in health care settings often contains a moral component and has been shown to be associated with burnout (Lützén et al. 2003; Glasberg et al. 2006, 2007). Given the high rates of burnout, psychosocial distress, and compassion fatigue among medical staff, it is imperative to further explore the potential role of chaplaincy in decreasing these detrimental outcomes (Brindley et al. 2012; El-bar et al. 2013; Hooper et al. 2010; Lyckholm 2001; Najjar et al. 2009; Shanafelt and Dyrbye 2012; Sherman et al. 2006). Future studies should further explore why despite nursing staff knowing that chaplains provide spiritual support to hospital staff, rarely take advantage of this resource and talk with a chaplain during stressful situations at work.

\section{Limitations}

Our study is not without limitations. We conducted a cross-sectional, anonymous survey utilizing a purposive sampling strategy targeting nursing staff who have routine access to a chaplain through daily rounds. We did not implement a probability sampling method, which would have enhanced the external validity of our findings. Moreover, the median age of 36 for the participants in our study is younger than the 42.8 median reported by the Bureau of Labor Statistics (2017) for hospital employees, which further limits the generalizability of our findings to younger medical employees in the hospital setting. Another limitation is the small sample size. Future studies may consider sending electronic survey links to improve survey response rates. Online survey methodology would ease the burden of completing a survey during working hours for staff who are already stressed. However, even with the small sample size, we were able to answer our most important research questions. Future studies utilizing larger sample sizes need to be conducted to characterize better the relationship between interacting with a chaplain and indicators of stress in hospital staff. A strength of the study was that the instruments used had excellent psychometric properties including validity and reliability, which enhances the study's findings.

\section{Conclusion}

Nursing staff are often confronted with death and dying and have to make difficult decisions, which may contribute to increased stress levels. Chaplains provide patients and families with a multitude of essential services including moral, emotional, psychological, religious and spiritual support. Our study shows that chaplains in hospital settings may also have a unique opportunity to impact nursing staff wellbeing at work. Given the focus on decreasing employee stress, burnout, and turnover 
rate, improving access to chaplaincy may be a cost-effective means of improving satisfaction.

Acknowledgements No funding was obtained to conduct the study.

\section{Compliance with Ethical Standards}

Conflict of interest The authors declare that they have no conflict of interest.

Human and Animal Rights All procedures performed in studies involving human participants were in accordance with the ethical standards of the institutional and/or national research committee and with the 1964 Declaration of Helsinki and its later amendments or comparable ethical standards.

Informed Consent Our study was under exempt status and did not require Informed consent from individual participants included in the study. This article does not contain any studies with animals performed by any of the authors.

\section{References}

Adams, R. E., Boscarino, J. A., \& Figley, C. R. (2006). Compassion fatigue and psychological distress among social workers: A validation study. American Journal of Orthopsychiatry, 76(1), 103-108. https://doi.org/10.1037/0002-9432.76.1.103.

Brindley, P. G., Patel, B., \& Farnan, P. A. (2012). Psychological Burnout in acute care medicine: "Physician Heal Thyself". In J. L. Vincent (Ed.), Annual update in intensive care and emergency medicine 2012 (pp. 811-818). Berlin: Springer. https://doi.org/10.1007/978-3-642-25716-2_73.

Bureau of Labor Statistics (2017) U.S. Department of Labor, Occupational Outlook Handbook, 20162017 Edition, Labor Force Statistics from the Current Population Survey, on the internet at https:// www.bls.gov/cps/cpsaat18b.htm. Accessed on September 15, 2017.

Campbell, D. A., Sonnad, S. S., Eckhauser, F. E., Campbell, K. K., \& Greenfield, L. J. (2001). Burnout among American surgeons. Surgery, 130(4), 696-705. https://doi.org/10.1067/msy.2001.116676.

Chang, B. H., Stein, N. R., Trevino, K., Stewart, M., Hendricks, A., \& Skarf, L. M. (2012). End-oflife spiritual care at a VA medical center: Chaplains' perspectives. Palliative and Supportive Care, 10(4), 273-278. https://doi.org/10.1017/S1478951511001003.

Charlescraft, A. S., Tartaglia, A., Dodd-McCue, D., \& Barker, S. B. (2010). When caring hurts... A pilot study supporting compassion-fatigued pediatric critical care nurses. Chaplaincy Today, 26(2), $16-25$.

Cohen, S. (1988). Perceived stress in a probability sample of the United States. In S. Spacapan \& S. Oskamp (Eds.), The social psychology of health (pp. 31-67). Thousand Oaks, CA, US: Sage Publications Inc.

Coomber, B., \& Louise Barriball, K. (2007). Impact of job satisfaction components on intent to leave and turnover for hospital-based nurses: A review of the research literature. International Journal of Nursing Studies, 44(2), 297-314. https://doi.org/10.1016/j.ijnurstu.2006.02.004.

Cronqvist, A., Lützén, K., \& Nyström, M. (2006). Nurses' lived experiences of moral stress support in the intensive care context. Journal of Nursing Management, 14(5), 405-413. https://doi.org/10.111 1/j.1365-2934.2006.00631.x.

Cunningham, C. J., Panda, M., Lambert, J., Daniel, G., \& DeMars, K. (2017). Perceptions of chaplains' value and impact within hospital care teams. Journal of Religion and Health, 56(4), 1231-1247.

Dahlqvist, V., Eriksson, S., Glasberg, A.-L., Lindahl, E., Tzén, K. L., Strandberg, G., et al. (2007). Development of the perceptions of conscience questionnaire. Nursing Ethics, 14(2), 181-193. https://doi. org/10.1177/0969733007073700.

El-bar, N., Levy, A., Wald, H. S., \& Biderman, A. (2013). Compassion fatigue, burnout and compassion satisfaction among family physicians in the Negev area: A cross-sectional study. Israel Journal of Health Policy Research, 2, 31. https://doi.org/10.1186/2045-4015-2-31. 
Fitchett, G. (2017). Recent progress in chaplaincy-related research. Journal of Pastoral Care \& Counseling, 71(3), 163-175.

Glasberg, A.-L., Eriksson, S., Dahlqvist, V., Lindahl, E., Strandberg, G., Söderberg, A., et al. (2006). Development and initial validation of the stress of conscience questionnaire. Nursing Ethics, 13(6), 633-648. https://doi.org/10.1177/0969733006069698.

Glasberg, A. L., Eriksson, S., \& Norberg, A. (2007). Burnout and "stress of conscience" among healthcare personnel. Journal of Advanced Nursing, 57(4), 392-403. https://doi.org/10.111 1/j.1365-2648.2007.04111.x.

Grunfeld, E., Whelan, T. J., Zitzelsberger, L., Willan, A. R., Montesanto, B., \& Evans, W. K. (2000). Cancer care workers in Ontario: Prevalence of burnout, job stress and job satisfaction. Canadian Medical Association Journal, 163(2), 166-169.

Hemming, P., Teague, P. J., Crowe, T., \& Levine, R. (2016). Chaplains on the medical team: A qualitative analysis of an interprofessional curriculum for internal medicine residents and chaplain interns. Journal of Religion and Health, 55(2), 560-571.

Hooper, C., Craig, J., Janvrin, D. R., Wetsel, M. A., \& Reimels, E. (2010). Compassion satisfaction, burnout, and compassion fatigue among emergency nurses compared with nurses in other selected inpatient specialties. Journal of Emergency Nursing, 36(5), 420-427. https://doi.org/10.1016/j. jen.2009.11.027.

Jensen, A., \& Lidell, E. (2009). The influence of conscience in nursing. Nursing Ethics, 16(1), 31-42. https://doi.org/10.1177/0969733008097988.

Jeuland, J., Fitchett, G., Schulman-Green, D., \& Kapo, J. (2017). Chaplains working in palliative care: Who they are and what they do. Journal of Palliative Medicine, 20(5), 502-508.

Lützén, K., Cronqvist, A., Magnusson, A., \& Andersson, L. (2003). Moral stress: Synthesis of a concept. Nursing Ethics, 10(3), 312-322. https://doi.org/10.1191/0969733003ne608oa.

Lyckholm, L. (2001). Dealing with stress, burnout, and grief in the practice of oncology. The Lancet Oncology, 2(12), 750-755. https://doi.org/10.1016/S1470-2045(01)00590-3.

Najjar, N., Davis, L. W., Beck-Coon, K., \& Doebbeling, C. C. (2009). Compassion fatigue: A review of the research to date and relevance to cancer-care providers. Journal of Health Psychology, 14(2), 267-277. https://doi.org/10.1177/1359105308100211.

Pereira, S. M., Fonseca, A. M., \& Carvalho, A. S. (2011). Burnout in palliative care: A systematic review. Nursing Ethics, 18(3), 317-326. https://doi.org/10.1177/0969733011398092.

Pfaff, K. A., Freeman-Gibb, L., Patrick, L. J., DiBiase, R., \& Moretti, O. (2017). Reducing the "cost of caring" in cancer care: Evaluation of a pilot interprofessional compassion fatigue resiliency programme. Journal of Interprofessional Care, 31(4), 512-519.

Rathert, C., May, D. R., \& Chung, H. S. (2016). Nurse moral distress: A survey identifying predictors and potential interventions. International Journal of Nursing Studies, 53, 39-49.

Sajjadi, S., Norena, M., Wong, H., \& Dodek, P. (2017). Moral distress and burnout in internal medicine residents. Canadian Medical Education Journal, 8(1), e36-e43.

Shanafelt, T., \& Dyrbye, L. (2012). Oncologist burnout: Causes, consequences, and responses. Journal of Clinical Oncology, 30(11), 1235-1241. https://doi.org/10.1200/JCO.2011.39.7380.

Sherman, A. C., Edwards, D., Simonton, S., \& Mehta, P. (2006). Caregiver stress and burnout in an oncology unit. Palliative and Supportive Care, 4(1), 65-80. https://doi.org/10.1017/S147895150 6060081.

Taylor, J. J., Hodgson, J. L., Kolobova, I., Lamson, A. L., Sira, N., \& Musick, D. (2015). Exploring the phenomenon of spiritual care between hospital chaplains and hospital based healthcare providers. Journal of Health Care Chaplaincy, 21(3), 91-107. https://doi.org/10.1080/08854726.2015.10153 02.

Whitebird, R. R., Asche, S. E., Thompson, G. L., Rossom, R., \& Heinrich, R. (2013). Stress, burnout, compassion fatigue, and mental health in hospice workers in Minnesota. Journal of Palliative Medicine, 16(12), 1534-1539. https://doi.org/10.1089/jpm.2013.0202.

Zuzelo, P. R. (2007). Exploring the moral distress of registered nurses. Nursing Ethics, 14(3), 344-359. https://doi.org/10.1177/0969733007075870.

Publisher's Note Springer Nature remains neutral with regard to jurisdictional claims in published maps and institutional affiliations. 